\title{
Enfermedad de Crohn. Enfoque diagnóstico y terapéutico de las primeras visitas
}

\section{Diagnostic and Therapeutic Approaches for First Visits of Patients with Crohn's Disease}

Juan Ricardo Márquez Velásquez, MD. ${ }^{1}$

\begin{abstract}
Coloproctólogo Instituto de Coloproctología ICO S.A.S. Clínica Las Américas. Medellín, Colombia. E-mail: juanmarquezv@gmail.com
\end{abstract}

Fecha recibido: $12-02-14$ Fecha aceptado: 05-11-14

\begin{abstract}
Resumen
La enfermedad de Crohn (EC) es protagonista fundamental de la llamada enfermedad inflamatoria intestinal (EEI), término con el que se conocen varias entidades cuyo origen es multifactorial y se caracterizan por un fenómeno inflamatorio, crónico, recurrente con diferentes grados de afectación sobre el tubo digestivo; pero además con compromiso potencial de otros órganos.

En la última década ha habido un renovado interés en dichas entidades, debido a un auge en medicamentos novedosos, a pesar de lo cual estas siguen siendo incurables. Lo anterior asociado a una incidencia creciente de dicha patología en nuestro país nos obliga tanto cientíica como moralmente a elaborar unos lineamientos básicos, prácticos con listas de chequeo adaptadas a nuestro medio para el enfoque diagnóstico y seguimiento a través de las primeras consultas del paciente con EC.
\end{abstract}

Palabras clave

Enfermedad de Crohn, enfermedad inflamatoria intestinal, lista de chequeo, vacunación, tuberculosis.

\begin{abstract}
Crohn's disease (CD) is the fundamental protagonist of so-called Inflammatory Bowel Disease (IBD). This is a term by which several entities are known. Its origin is multifactorial. It is characterized by chronic and recurrent inflammation with different degrees of involvement of the gastrointestinal tract, but also with potential commitment of other organs.

In the last decade there has been a renewed interest in these entities due to a boom in innovative medicines. Despite these medications, CD and IBD remain incurable. The increasing incidence of $C D$ in our country requires us both scientifically and morally to develop basic, practical guidelines with checklists adapted to our environment for the diagnosis and management of $C D$ through the first consultations of patients.
\end{abstract}

\section{Keywords}

Crohn's disease, inflammatory bowel disease, checklist, vaccination, tuberculosis.

\section{INTRODUCCIÓN}

La enfermedad de Crohn (EC) hace parte de la llamada enfermedad inflamatoria intestinal (EII) la cual es una respuesta inmune desproporcionada de la mucosa intestinal frente a un estímulo medioambiental causado por enteropatógenos en un individuo genética e inmunológicamente susceptible, que conlleva a una respuesta inflamatoria incontrolada de la mucosa intestinal, la cual es crónica, progresiva y destructiva.

Se caracteriza por el compromiso transmural y fistulizante, que puede afectar todo el tracto digestivo y la región perineal. Su síntoma principal es la diarrea con o sin sangre, pero asociado a manifestaciones heterogéneas con perio- 
dos de exacerbación y remisión, que incluyen dolor abdominal, pérdida de peso, anemia, fiebre, anorexia, astenia y, en algunos casos, complicaciones serias como obstrucción intestinal, fístulas de predominio perianal en $15 \%$, que generalmente son complejas y suelen no cicatrizar, rectovaginales en $10 \%$ y abscesos $(1,2)$; además, manifestaciones extraintestinales, las cuales son más frecuentes en la presentación de EC colónico (3).

Definitivamente con el desarrollo y modernización de una sociedad, la EII debuta inicialmente con un aumento de la colitis ulcerativa (CU) estabilizándose en un cierto número de afectados y después de un intervalo variable de unos 10 años aparece la EC, incrementando su número, incluso en valores mayores que la CU (4). Es por esto que en la actualidad, en países desarrollados, la EII ocupa uno de los primeros lugares dentro de la patología gastrointestinal en incidencia y prevalencia con cifras y rangos variables de 4-7/ 100.000 habitantes/año y 120-200/100.000 pacientes de (CU), respectivamente y de $8-12 / 100.000$ habitantes/año y 50-200/100.000 pacientes en EC, respectivamente; con un total aproximado de 1,4 millones de personas en EUA y 2,2 millones en Europa sufriendo de estas enfermedades (3-6).

Es probable que el aumento de incidencia de estas enfermedades se deba a un conjunto de factores medioambientales y económicos que incluyen: mejoría en las condiciones sanitarias, dieta (no solo más rica en grasa y carbohidratos, sino más baja en fibra junto a adiciones de químicos y mejoría en los sistemas de conservación de esta), disminución de las infecciones en la infancia debido a uso masivo de antibióticos de amplio espectro, polivacunaciones, mejoría de los sistemas de saneamiento ambiental (acueducto, alcantarillado, etc.), y otros muchos cambios, incluidos la disminución en el tamaño del núcleo familiar, el sedentarismo, la obesidad y la contaminación medioambiental (4).

Existen datos preocupantes que fueron los que me motivaron a escribir este artículo. En el estudio IMPACT (7) (Estudio descriptivo colaborativo entre 24 países dentro de la Unión Europea en donde 4.900 pacientes con EII participaron a través de encuestas) se determinó que la mayoría de los pacientes fue diagnosticado a tiempo (1-3 años), pero $18 \%$ esperó más de 5 años, una mayoría importante, y $64 \%$ necesitó atención médica de emergencia antes de su diagnóstico. La tasa de hospitalización es extremadamente alta, $85 \%$ en los últimos 5 años, la mitad de las personas con EII tienen la enfermedad activa al momento de responder la encuesta. El $74 \%$ ha pedido licencias en sus trabajos durante el último año a causa de la EII, de las cuales, $26 \%$ de ellas duró más de 25 días (7).

Colombia no es ajena a este hecho; de acuerdo a un estudio retrospectivo entre 1968 y 1990 en 2 centros hospitalarios en Bogotá (8), de manera descriptiva se sugirió que existía una relación de 9 casos de CU por cada caso de EC. Casi veinte años más tarde en un estudio observacional descriptivo realizado en el Hospital Pablo Tobón Uribe de Medellín esta relación se ha estrechado a 4,9 casos de CU por cada paciente con EC (9); lo cual quiere decir que aunque ambas patologías han aumentado en incidencia, la EC ha crecido proporcionalmente más y ha ido cerrando la brecha.

Basado en la literatura y las diferentes guías existentes propondré un derrotero claro, práctico, ajustado a nuestro medio y necesidades, con los pasos básicos para el enfoque diagnóstico y seguimiento de las primeras consultas del paciente con EC junto al abordaje terapéutico, sin profundizar en los diferentes aspectos ya que no es el objetivo de este artículo. Al final el lector encontrará una lista de chequeo, la cual, y si así lo considera, podrá ser libremente incorporada a su formato de historia clínica.

\section{LA PRIMERA EVALUACIÓN}

La primera consulta de un paciente con sospecha de padecer una EII o con el diagnóstico ya confirmado de una EC es un momento especial pero también un reto tanto para el clínico como para el paciente, porque aparte de iniciar la construcción de una empatía, ingrediente fundamental en cualquier relación médico-paciente, en este ámbito es aún más importante por las implicaciones que conlleva tener un diagnóstico como este.

Puede llegar remitido con o sin un diagnóstico hecho, frecuentemente con una historia clínica tórpida, con su enfermedad activa, desconociendo por completo lo que tiene, solo con una serie de síntomas y sin saber claramente cuándo iniciaron. Pero con frecuencia es una persona que conoce su diagnóstico (o cree conocerlo a través de diferentes fuentes la más socorrida en la actualidad: el internet), se le han practicado infinidad de exámenes, ha sido polimedicado, con varias hospitalizaciones y hasta cirugías pero, peor aún, manejado por múltiples médicos, sin un derrotero terapéutico claro ni objetivos definidos; al final con un pronóstico incierto pero ciertamente sombrío. Independientemente del tipo de paciente que esté sentado frente a nosotros, el común denominador cuando llega a esa "tan esperada" primera consulta con el especialista es bajo una gran dosis de incertidumbre, con altas expectativas pero ciertamente con gran terror.

La empatía del médico con el paciente y la familia es fundamental. La prisa del profesional y los cortos tiempos impuestos por las entidades de salud pueden llevar al traste con la construcción de una adecuada relación médicopaciente, lo que dificulta el posterior examen físico y el tratamiento, más aún si es quirúrgico donde la confianza en el médico juega un factor fundamental en la aceptación, recuperación y reintegración a su vida cotidiana. 
El especialista debe intentar confirmar en esta primera consulta el diagnóstico de la enfermedad, el grado de actividad inflamatoria, obtener información clara sobre exámenes y manejos terapéuticos del pasado, con el objetivo de diseñar un cronograma terapéutico para finalmente ofrecerle al paciente información objetiva sobre su tratamiento y pronóstico con metas precisas a corto, mediano y largo plazo (10) (tabla 1).

Tabla 1. Características diagnósticas de la enfermedad de Crohn (26).

\section{Historia médica (síntomas deben estar presentes por 4-6 semanas)}

Diarrea con dolor abdominal y pérdida de peso, frecuentemente nocturna, sangrado rectal oculto o evidente, retraso de pubertad y/o en el crecimiento (en infancia o pubertad).

Historia familiar de enfermedad inflamatoria intestinal.

Síntomas sospechosos de manifestaciones extraintestinales (articulaciones, ojos, piel)

\section{Examen físico}

Dolor y/o masa abdominal (sugestivo de compromiso ileocecal o absceso), enfermedad perianal (fisuras, fistula, abscesos perirrectales, colgajos cutáneos).

Signos de enfermedad extraintestinal (dolor, rubor, edema calor y rigidez articular, eritema nodoso, ojo enrojecido, etc.

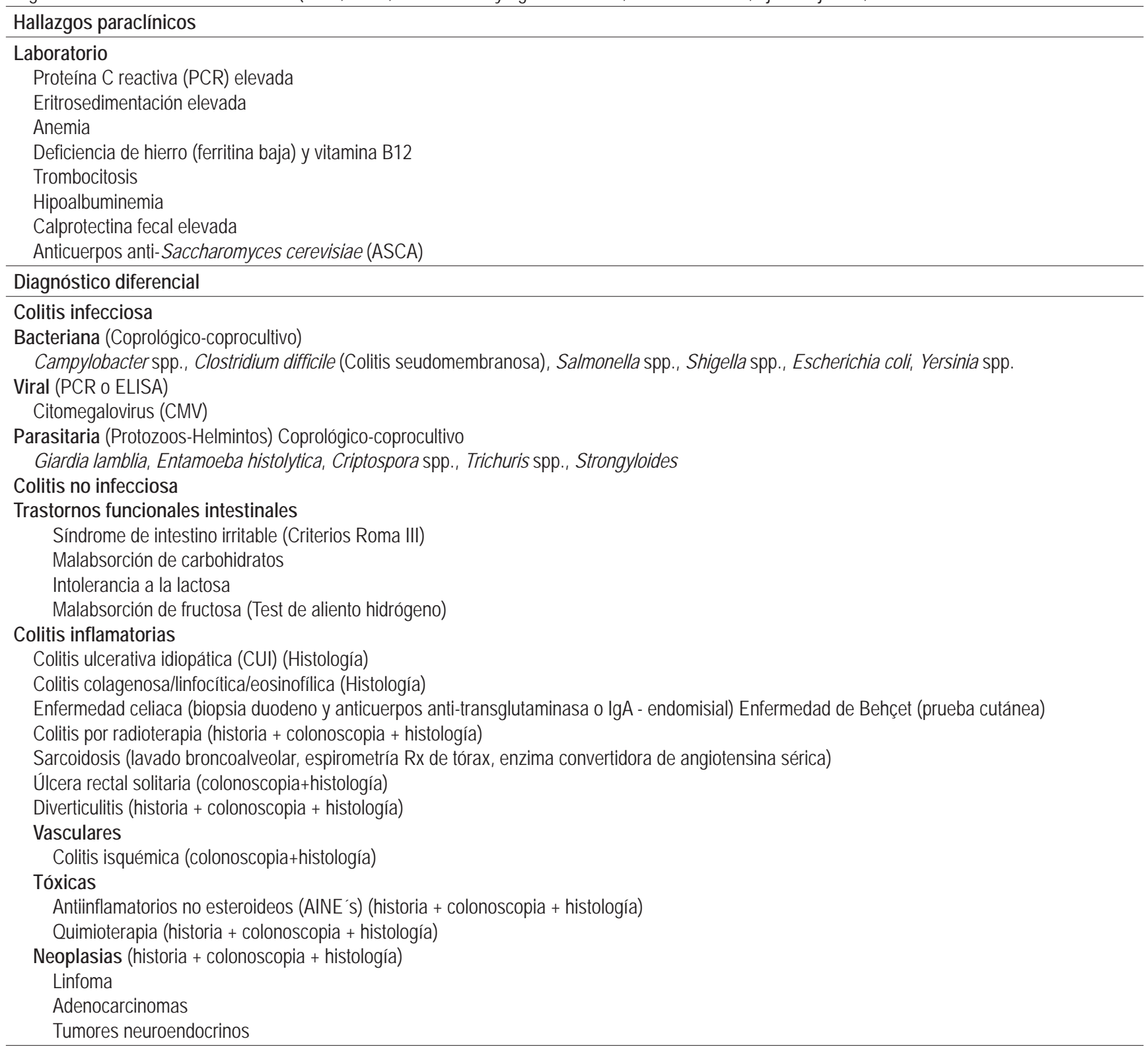


Tabla 1. Características diagnósticas de la enfermedad de Crohn (26). Continuación

\author{
Características endoscópicas \\ Patrón inflamatorio discontinuo ("lesiones saltonas") o en empedrado (mucosa hipertrófica no ulcerada separada por úlceras). Estenosis, masas que \\ obligan a descartar neoplasia \\ Características histológicas [por lo menos 2 biopsias de los 6 segmentos del colon (recto, sigmoides, descendente, transverso, ascendente y \\ ciego) más el íleon]. \\ Inflamación crónica focal discontinua \\ Arquitectura focal críptica irregular \\ Inflamación transmural \\ Granulomas \\ Aumento de los linfocitos intraepiteliales \\ Imagenología \\ Ecografía abdominal / Enterografía por resonancia nuclear magnética (RNM) o tomografía axial computarizada (TAC) \\ Engrosamiento y edema de pared intestinal \\ Compromiso de intestino delgado \\ Úlceras profundas (las úlceras tempranas y superficiales no son detectadas) \\ Estenosis, abscesos \\ Fístulas enterocólicas, enteroentéricas, enterocutáneas \\ Infiltración grasa de la pared intestinal e hipertrofia grasa mesentérica (grasa reptante) \\ Hallazgos extraluminales \\ Linfadenitis mesentérica
}

\section{Paso 1}

\section{Obtención de antecedentes clínicos}

Datos importantes que se deben siempre preguntar son: sexo, raza, edad de inicio de la enfermedad, localización, extensión y duración de esta, manifestaciones clínicas predominantes, historia familiar de EII, historial de vacunaciones, antecedentes gineco-obstétricos (fecha última menstruación), tipo de tratamiento que recibe en la actualidad, complicaciones con este, etc.

Pudiera ser importante utilizar un cuestionario de calidad de vida relacionada a la salud (HRQOL por su sigla en inglés) validado para obtener la información sobre la calidad de vida actual, la historia laboral, familiar y socioeconómica de una manera objetiva pero siempre DESPUÉS de establecer totalmente el diagnóstico, puesto que dicho índice está diseñado específicamente para la EII, no sería válido en ningún otro caso.

La forma corta del cuestionario de enfermedad inflamatoria intestinal (IBDQ) está compuesta de 10 preguntas y básicamente se usa para determinar el impacto de la enfermedad en la calidad de vida del paciente (23). Con este sencillo y corto ejercicio podemos rápidamente estratificar la severidad, agresividad y el pronóstico de la enfermedad del paciente en cuestión ya que todos los puntaje se reportan en una escala de 7 puntos $(1=$ HRQOL mala, 7 = HRQOL óptima) (30) (tabla 2).

Existen datos en la historia clínica de un paciente que desde el principio lo colocan en un estado de alto riesgo y mal pronóstico con la probable necesidad de instaurar tempranamente tratamiento con biológicos, tales como: edad menor de 40 años al inicio de la enfermedad, fumador, enfermedad perianal o gastroduodenal, compromiso intestinal extenso $(>100 \mathrm{~cm})$, enfermedad fistulizante, ulceración endoscópica profunda, uso de esteroides, hospitalizaciones y cirugías, pérdida de peso, manifestaciones extraintestinales como sacroileítis, espondilitis anquilosante, pioderma gangrenoso y uveítis.

\section{Paso 2}

\section{Evaluación de actividad inflamatoria}

A todo paciente lo debemos estadiar de acuerdo a la presentación de la enfermedad, su localización y el tipo de compromiso de esta (inflamatorio, estenosante, fistulizante) siendo la ileocolonoscopia con biopsias el examen basal sobre el cual gira el diagnóstico y posterior manejo.

El riesgo de presentar enfermedad fistulizante es de 20 a $40 \%$. El curso clínico de las fístulas es variable y depende de su localización y complejidad siendo las perianales las más difíciles para cicatrizar (11).

Los síntomas, exámenes de laboratorio (incluida la medición de marcadores inflamatorios), serologías y estudios imagenológicos nos ayudan a establecer el grado y la extensión del compromiso inflamatorio, aunque lastimosamente no existe el examen "gold standard" (12).

Las manifestaciones extraintestinales son más frecuentes en EC especialmente cuando afecta el colon (11), ocurriendo en $21-36 \%$ de pacientes con EII, las cuales se pueden dividir en 3 grupos: 
Tabla 2. Forma corta del cuestionario de enfermedad inflamatoria intestinal (IBDQ).

1. ¿Qué tan frecuentemente tiene una sensación de fatiga o de estar cansado y maltratado ha sido un problema para usted en las dos últimas semanas?

2. ¿Qué tan frecuentemente en las dos últimas semanas ha tenido usted que retrasar o cancelar un compromiso social debido a sus problemas intestinales?

3. ¿Qué tanta dificultad ha tenido usted debido a sus problemas intestinales para realizar actividades deportivas o recreativas que hubiera querido hacer en las dos últimas semanas?

4. ¿Qué tan frecuente en las dos últimas semanas se ha sentido afectado (a) por dolor abdominal?

5. ¿Qué tan frecuente en las dos últimas semanas se ha sentido deprimido (a) o descorazonado?

6. ¿Globalmente, en las dos últimas semanas que tanto problema ha tenido pasando grandes cantidades de gas?

7. ¿Globalmente, en las dos últimas semanas que tanto problema ha tenido conservando o logrando llegar al peso en el cual usted quisiera estar?

8. ¿Qué tan frecuente en las dos últimas semanas se ha sentido relajado o libre de tensión?

9. ¿Qué tanta cantidad de tiempo en las últimas dos semanas ha tenido problemas con la sensación de tener que ir al sanitario aun sabiendo que su intestino estaba vacío?

10. ¿Qué tanta cantidad de tiempo en las últimas dos semanas se ha sentido bravo como resultado de su problema intestinal?

1. Trastornos que afectan la piel (pioderma gangrenoso y eritema nodoso), ojos (uveítis, iritis, epiescleritis y escleritis), articulaciones (son las manifestaciones extraintestinales más frecuentes e incluyen trastornos reumáticos tales como artropatía periférica y axial, espondilitis anquilosante y del metabolismo óseo) y boca. Usualmente ocurren en pacientes con EC colónico y la actividad de su enfermedad intestinal es paralela a la extraintestinal.

2. Complicaciones secundarias (cálculos renales, uropatía obstructiva, malabsorción y colelitiasis) a la EII o extensión de esta; más comúnmente en pacientes con EC que CU.

3. Otros trastornos que no pueden ser caracterizados en ninguno de los grupos anteriores (osteoporosis, enfermedades hepáticas, amiloidosis, complicaciones vasculares, hematológicas, pulmonares, cardíacas y neurológicas).

\section{Índices de gravedad}

Para el primer criterio clínico nos basamos en la clasificación de Montreal (13) la cual se divide en edad de inicio de la enfermedad (Age), localización de los segmentos intestinales comprometidos (Location), finalmente comportamiento y severidad inflamatoria (Behaivor).

\begin{tabular}{|c|c|c|}
\hline $\begin{array}{l}\text { Edad de diagnóstico } \\
\text { (A) }\end{array}$ & Localización (L) & Comportamiento (B) \\
\hline A1: Menor de 16 años & L1: Íleon & $\begin{array}{l}\text { B1: No estenosante, ni } \\
\text { penetrante (inflamatorio) }\end{array}$ \\
\hline A2: Entre 17 y 40 años & L2: Colon & B2: Estenosante \\
\hline \multirow[t]{2}{*}{ A3: Mayor de 40 años } & L3: Îleon y colon & $\begin{array}{l}\text { B3: Penetrante } \\
\text { (fistulizante) }\end{array}$ \\
\hline & $\begin{array}{l}\text { L4: Digestivo } \\
\text { superior aislado }\end{array}$ & P: Enfermedad perineal \\
\hline
\end{tabular}

\section{Índice de actividad de la EC}

Menciono más como un dato de interés, el índice de actividad de la EC (CDAI por sus siglas en inglés) (14), ya que es usado en estudios clínicos y raramente en la práctica clínica cotidiana; pero es el sistema de puntuación en el cual se basan todos los artículos científicos para elaborar sus conclusiones y recomendaciones. Se ha diseñado para medir la eficacia de la terapia médica, seguimiento clínico y evaluación de la gravedad de la enfermedad.

El cálculo del índice (se puede conseguir en línea una calculadora del CDAI en www.ibdjohn.com/cdai/) puede clasificar la actividad según el valor obtenido, como se enumera a continuación:

1. Respuesta: Disminución 100 puntos en el CDAI

2. Remisión: CDAI $<150$ puntos

3. Actividad leve: CDAI 151-219 puntos

4. Actividad moderada: CDAI 220-450 puntos

5. Actividad grave: $\mathrm{CDAI}>450$.

\section{Índice de Harvey-Bradshaw (IHB)}

También conocido como el índice simplificado o el CDAI modificado. El índice de Harvey-Bradshaw es el más práctico y fácil de usar. Es de frecuente uso en la práctica clínica. Se basa en variables subjetivas y clínicas. Solo se utilizan 5 variables del CDAI, excluyendo el uso de antidiarreico, hematocrito y variación del peso. Evalúa los parámetros en las 24 horas precedentes, es fácil/rápido y permite el control ambulatorio, pero esto lo hace menos seguro pues puede cambiar de un día a otro. Muestra una excelente correlación con el CDAI. Sería útil en el uso clínico y en estudios clínicos, como lo demostró su aplicación en PRECISE 1 y 2 . Tiene las mismas desventajas y limitaciones del CDAI (32). 


\section{Bienestar general \\ $0=$ en general bueno \\ $1=$ leve compromiso \\ $2=$ moderado \\ $3=$ malo \\ $4=$ terrible \\ 2. Dolor abdominal \\ $0=$ ausente \\ $1=$ leve \\ $2=$ moderado \\ $3=$ severo}

3. Número de deposiciones blandas o líquidas por día (1 por cada deposición)

4. Masa abdominal

$0=$ ausente

$1=$ cuestionable

$2=$ definida

5. Complicaciones (1 punto por ítem)

Artralgia, uveítis, eritema nodoso, úlceras aftoides

Pioderma gangrenoso, fisura anal, fístula nueva, abscesos

\begin{tabular}{l}
\multicolumn{1}{c}{ PUNTAJE TOTAL (Sumatoria de preguntas 1-5) IHB: } \\
\hline Remisión $<5$ \\
Enfermedad leve 5-7 \\
Enfermedad moderada 8-16 \\
Enfermedad grave $>16$ \\
\hline
\end{tabular}

Adaptada de Harvey RF, Bradshaw JM. 1980 (32).

\section{Marcadores bioquímicos (biomarcadores)}

La proteína $\mathrm{C}$ reactiva (PCR) es un reactante de fase aguda muy sensible aumentándose en caso de inflamación, infección o lesión tisular. En EC es un marcador acertado, se eleva cuando hay inflamación activa y se correlaciona bien con el CDAI (15). Una PCR baja puede indicar que la EC está en fase de inactividad o quiescente aunque esto es parcialmente cierto ya que hasta $50 \%$ de pacientes con EC activa no muestran elevación de esta, a pesar de tener una inflamación activa documentada.

La calprotectina fecal es una proteína ubicada en el citosol de los neutrófilos y macrófagos que se libera en situaciones de daño celular, siendo detectada en las heces en un lapso de hasta una semana a temperatura ambiente. Es un marcador que se correlaciona muy bien con los índices de actividad clínica, endoscópica e histológica de la enfermedad y tiene la capacidad de evaluar la eficacia al tratamiento instaurado así como discriminar la actividad inflamatoria entre ausente $(<50 \mathrm{ug} / \mathrm{g})$, moderada (50$150 \mathrm{ug} / \mathrm{g})$, grave (>150 ug/g). En caso de encontrar niveles $>250 \mathrm{ug} / \mathrm{g}$ indica que la enfermedad aparte de haberse activado se está asociando a una inflamación grave de la mucosa $(16,28)$.
De todas maneras la ileocolonoscopia es el examen de elección para determinar el grado de inflamación mucosa.

\section{Serología}

Una serie de marcadores, péptidos antimicrobianos y anticuerpos se han estudiado para poder determinar y diferenciar entre CUI o EC así como definir su pronóstico, pero ninguno es lo suficientemente sensible ni específico para ser usado por sí solo. Los anticuerpos anti-Saccharomyces cerevisiae (ASCA) tienen una sensibilidad de $60 \%$ para EC pero pueden estar positivos hasta en $15 \%$ en caso de CUI; mientras que los anticuerpos anticitoplasma antineutrofílico perinuclear ( $\mathrm{pANCA}$ ) tienen una sensibilidad entre $40 \%$ y $60 \%$ para CUI.

Para las dos combinaciones ANCA-/ASCAS+ y ANCA+/ASCAS-, se establece una sensibilidad de 50\% y una especificidad de $92-97 \%$ para EC y para CUI una sensibilidad de $45 \%$ y una especificidad de $81-98 \%$ (27).

El fijador del nucleótido de la oligomerización del dominio 2 (NOD2) se ha asociado a EC en personas jóvenes, con enfermedad extensa y fibroestenosante, lo mismo que el ASCA se asocia a enfermedad agresiva y a necesidad de cirugía. El Anti-OmpC se asocia a fibroestenosis, enfermedad perforada y a cirugía del intestino delgado (10).

\section{Paso 3}

\section{Historia de vacunación y administración de vacunas requeridas}

El uso de medicación tal como esteroides, inmunosupresores y biológicos favorecen la aparición de infecciones oportunistas y gérmenes que pueden ser prevenibles con vacunación.

Las vacunas de virus vivos están contraindicadas en pacientes que tengan alguna condición que los defina como inmunosuprimidos:

1. Tratamiento con glucocorticoides (prednisona o equivalente $>20 \mathrm{mg} /$ día o $2 \mathrm{mg} / \mathrm{kg} /$ día durante $>2$ semanas y/o entre los 3 meses después de haberlos suspendido.

2. Tratamiento actual con dosis efectivas de 6-MP/AZA o entre los 3 meses después de haberlos suspendido.

3. Tratamiento con metotrexate o entre los 3 meses después de haberlo suspendido.

4. Tratamiento con inhibidores del factor de necrosis tumoral o entre los 3 meses después de haberlos suspendido.

5. Malnutrición proteico-calórica grave.

Por lo tanto, una historia de vacunación se debe elaborar en la primera consulta y en el momento oportuno revisar los 
títulos de anticuerpos para parotiditis, sarampión y rubéola (MMR) varicela, hepatitis A y B (31).

\section{Enfoque de acuerdo a resultado serológico de hepatitis $B$}

\begin{tabular}{ccccc}
\hline Transaminasas & AgHBs & AntiHBc & AntiHBs & Conducta \\
\hline $\begin{array}{c}\text { Normal } \\
\text { Normal }\end{array}$ & - & - & - & $\begin{array}{c}\text { Vacunar } \\
\text { Inmune por }\end{array}$ \\
Normal & - & + & - & $\begin{array}{c}\text { Infección oculta } \\
\text { infección natural }\end{array}$ \\
Normal & - & - & + & $\begin{array}{c}\text { Vacunado } \\
\text { Normal }\end{array}$ \\
Anormal & + & + & - & Portador crónico* \\
\hline
\end{tabular}

*Valoración por hepatología vs. infectología.

De acuerdo al Comité asesor para las prácticas de inmunización (ACIP) (17), a los pacientes con EC, y una vez se les documente la exposición y los niveles serológicos, se les debe administrar vacunas con una de las siguientes caracte- rísticas: inactivadas o polisacarídicas o toxoides, las cuales se pueden aplicar sin problemas de seguridad aunque su respuesta inmune es menor que en la población general. Las vacunas indicadas para este grupo de pacientes se enumeran en la tabla 3 pero el esquema recomendado para el adulto se esboza en la tabla 4.

Las vacunas contraindicadas son las hechas con miroorganismos vivos atenuados dentro de las cuales se incluyen:

- Triple vírica

- Varicela

- Rotavirus

- Cólera oral

- Fiebre amarilla

- Fiebre tifoidea oral (Ty21a)

- Antipoliomielitis oral.

Si no se va a iniciar la terapia biológica o inmunosupresora antes de un mes se pueden aplicar las vacunas de virus vivos atenuados (MMR, varicela y herpes zoster). Los infantes de madres con EII que recibieron biológicos durante el embarazo, tendrán niveles de estos hasta 6 meses después

Tabla 3. Recomendaciones de vacunas inactivas.

\begin{tabular}{|c|c|}
\hline Vacuna & Esquema recomendado \\
\hline DPT/TD & $\begin{array}{l}\text { Sustituya } 1 \text { dosis de DPT por un refuerzo de TD; luego refuerce con TD cada } 10 \text { años. Para pacientes >65 años administre } \\
\text { refuerzo de TD cada } 10 \text { años }\end{array}$ \\
\hline Hib & 1 dosis vía IM en niños mayores de 1 año y en adultos \\
\hline VIPa & 3 dosis de vacuna IM (a los 0, 2 y 6-12 meses) adultos que nunca recibieron antipoliomielitis oral (VOP) \\
\hline $\mathrm{PVH}$ & 3 dosis en niñas 12 a 26 años de edad \\
\hline Varicela & 2 dosis \\
\hline MMR & $\begin{array}{l}1 \text { a } 2 \text { dosis en pacientes } 19 \text { a } 49 \text { años de edad; } 1 \text { dosis después de } 50 \text { años de edad si hay factores de riesgo presentes } \\
\text { (médico, ocupacional o estilo de vida) }\end{array}$ \\
\hline Influenza & 1 dosis anual \\
\hline Neumococo & $\begin{array}{l}\text { Antineumocócica 23-v y 13v conjugada } 1 \text { a } 2 \text { dosis en pacientes } 19 \text { a } 49 \text { años de edad si hay factores de riesgo presentes } \\
\text { (médico, ocupacional o estilo de vida); } 1 \text { dosis en todos los pacientes > }>5 \text { años }\end{array}$ \\
\hline Virus hepatitis A & 2 dosis (espaciadas 6 meses) en pacientes con factores de riesgo presentes (médico, ocupacional o estilo de vida) \\
\hline Virus hepatitis B & $\begin{array}{l}3 \text { dosis (a 0,1 y } 6 \text { meses) en pacientes con factores de riesgo presentes } \\
\text { (médico, ocupacional o estilo de vida) }\end{array}$ \\
\hline Meningococo & $\begin{array}{l}\text { Antimeningocócica C y tetravalente (ACYW-135) conjugadas } 1 \text { o más } \\
\text { dosis en pacientes con factores de riesgo presentes (médico, ocupacional o estilo de vida) }\end{array}$ \\
\hline Vi & 1 dosis vía IM en niños mayores de 2 años y en adultos refuerzo c/2-3 años si persiste el riesgo \\
\hline $\begin{array}{l}\text { Encefalitis } \\
\text { japonesa }\end{array}$ & $\begin{array}{l}1 \mathrm{ml} \mathrm{SC} \text { en > de } 3 \text { años días } 0,7 \text { y } 14 \text { o 30. La última dosis debe administrarse } 10 \text { días antes de iniciar el viaje a la zona de } \\
\text { riesgo. Dosis de recuerdo: } 1 \mathrm{ml} \text { (en mayores de } 3 \text { años) cada } 2 \text { años }\end{array}$ \\
\hline $\begin{array}{l}\text { Encefalitis } \\
\text { centroeuropea }\end{array}$ & $\begin{array}{l}3 \text { dosis, administradas IM con un intervalo de 1-3 meses entre la } 1^{\mathrm{a}} \text { y la } 2^{\mathrm{a}} \text { (mínimo } 15 \text { días), y de 9-12 meses entre la } 2^{\mathrm{a}} \text { y la } 3^{\mathrm{a}} \text {. } \\
\text { La dosis de recuerdo se administra cada 3-5 años }\end{array}$ \\
\hline Antirrabia & $\begin{array}{l}\text { Tres dosis por vía intramuscular de } 1 \mathrm{ml} \text { de vacuna HDCV en los días (0), (7), (21 o 28) - postexposición (siempre tras el } \\
\text { tratamiento local correcto de la herida). 1. Individuos previamente inmunizados, solo requieren dosis con vacuna HDCV los días } \\
(0) \text { y (3). }\end{array}$ \\
\hline
\end{tabular}

DPT/TD: difteria, tétanos, pertussis (tosferina); MMR: sarampión, parotiditis, rubéola; VIPa: antipoliomielítica parenteral de potencia aumentada; PVH: papiloma virus humano; Hib: Haemophilus influenzae tipo b; Vi: fiebre tifoidea parenteral. 
Tabla 4. Esquema de vacunación recomendado para el adulto.

\begin{tabular}{|c|c|}
\hline Vacuna & Esquema recomendado \\
\hline DPT/TD & $\begin{array}{l}\text { Sustituya } 1 \text { dosis de DPT por un refuerzo de TD; luego refuerce con TD cada } 10 \text { años. Para pacientes > } 65 \text { años administré } \\
\text { refuerzo de TD cada } 10 \text { años }\end{array}$ \\
\hline $\mathrm{PVH}$ & 3 dosis en niñas 12 a 26 años de edad \\
\hline Varicela & 2 dosis \\
\hline MMR & $\begin{array}{l}1 \text { a } 2 \text { dosis en pacientes } 19 \text { a } 49 \text { años de edad. } 1 \text { dosis después de } 50 \text { años de edad si hay factores de riesgo presentes (médico, } \\
\text { ocupacional o estilo de vida) }\end{array}$ \\
\hline Influenza & 1 dosis anual \\
\hline Neumococo & $\begin{array}{l}1 \text { a } 2 \text { dosis en pacientes } 19 \text { a } 49 \text { años de edad si hay factores de riesgo presentes (médico, ocupacional o estilo de vida). Una } \\
\text { dosis en todos los pacientes > } 65 \text { años }\end{array}$ \\
\hline Virus hepatitis A & 2 dosis (espaciadas 6 meses) en pacientes con factores de riesgo presentes (médico, ocupacional o estilo de vida) \\
\hline Virus hepatitis B & 3 dosis (a 0,1 y 6 meses) en pacientes con factores de riesgo presentes (médico, ocupacional o estilo de vida) \\
\hline Meningococo & 10 más dosis en pacientes con factores de riesgo presentes (médico, ocupacional o estilo de vida) \\
\hline
\end{tabular}

DPT/TD: difteria, tétanos, pertussis (tosferina); MMR: sarampión, parotiditis, rubeola; PVH: papiloma virus humano.

del parto; la única vacuna con virus vivo que se recibe en este periodo es el rotavirus y por ende está contraindicada (25). Para la aplicación de vacunas atenuadas se requiere que hayan trascurrido mínimo 3 meses desde la finalización del medicamento inmunosupresor.

\section{Paso 4}

\section{Preparación para la terapia}

El objetivo final de la terapia contra la EII es un tratamiento antiinflamatorio e inmunosupresor dirigido a la respuesta inmune que causa el daño tisular. La azatioprina (AZA) se debe administrar en dosis de $2,5 \mathrm{mg} / \mathrm{kg}$ con monitoría a los 8 días del cuadro hemático particularmente el volumen corpuscular medio (VCM) ya que en nuestro medio no disponemos de la TioPurina Metil Transferasa (TPMT) y continuar con esta monitoría a los 15 días, al mes y luego cada 3 meses.

Se debe tener cuidado con el cáncer de piel no melanoma y displasia cervical asociada al papiloma virus humano $(\mathrm{PVH})$, especialmente en aquellos pacientes recibiendo azatioprina, por lo tanto, se recomienda el uso cotidiano de bloqueadores solares y revisiones anuales por dermatología y ginecología (10).

Los exámenes deben incluir medición de niveles de hierro, vitamina B12 y vitamina $\mathrm{D}$. Aquellos pacientes que recibieron de manera crónica esteroides (más de 6 semanas así no sean continuas de prednisolona a dosis mayores de 7,5 mg empiezan a tener osteopenia) se les debe hacer una densitometría ósea y considerar el uso de suplementos de calcio y vitamina $\mathrm{D}$.

A todo paciente al que se le planea iniciar terapia biológica se le deben tomar radiografías de tórax y PPD (en nuestro medio) vs. Quantiferon ${ }^{\circledR}$ ya que existe un riesgo entre 4-90 veces de reactivación de TBC con este tipo de medicamentos. Estas pruebas disminuyen la aparición de esta entidad 90\% de las veces al poder detectarla precozmente es sus estados latente vs. activa (24). A continuación se muestran dos esquemas prácticos tanto para la interpretación de la prueba (PPD) como para el tratamiento de acuerdo al resultado de esta (tablas 5 y 6) (31).

Tabla 5. Enfoque de acuerdo a resultado de PPD para inicio de terapia biológica.

\begin{tabular}{lll}
\hline \multicolumn{1}{c}{ Resultado PPD } & \multicolumn{1}{c}{ Acción } & \multicolumn{1}{c}{ Aplicación biológica } \\
\hline $\begin{array}{l}\text { PPD }<5 \text { MM } \\
\text { (negativo) }\end{array}$ & Ninguna & Inmediatamente \\
$\begin{array}{l}\text { PPD }>5 \text { MM } \\
\text { (positivo) }\end{array}$ & $\begin{array}{l}\text { Tratamiento de } \\
\text { TBC latente }\end{array}$ & $\begin{array}{l}\text { Al mes de haber comenzado } \\
\text { la profilaxis con esquema } \\
\text { aceptado }\end{array}$ \\
$\begin{array}{l}\text { RX tórax normal } \\
\text { PPD }>5 \text { MM }\end{array}$ & Tratamiento de & $\begin{array}{l}\text { Iniciar una vez infectología } \\
\text { (positivo) }\end{array}$ \\
TBC activa & TBC activa hasta & $\begin{array}{l}\text { vs. neumología confirme } \\
\text { resolución }\end{array}$ \\
\hline
\end{tabular}

Tabla 6. Esquemas de tratamiento de TBC latente.

\begin{tabular}{lll}
\hline \multicolumn{1}{c}{ Medicamento } & \multicolumn{1}{c}{ Dosis } & \multicolumn{1}{c}{ Duración } \\
\hline Isoniazida & $300 \mathrm{mg} /$ día & $6-9$ meses \\
Rifampicina & $600 \mathrm{mg} /$ día & 4 meses \\
Isoniazida + Rifampicina & $300 \mathrm{mg}+600 \mathrm{mg} /$ día & 3 meses \\
\hline
\end{tabular}

La terapia con bloqueadores del factor de necrosis tumoral se puede iniciar al mes después de haber comenzado la profilaxis con cualquiera de los esquemas propuestos anteriormente. De todas maneras, cualquier paciente que reciba esta terapia tiene mayor susceptibilidad de infectarse 
y enfermarse de TBC en cualquiera de sus formas (pulmonar, extrapulmonar, atípica, miliar, etc.), independiente de su estado serológico previo y es por esto que se debe poner especial cuidado en el seguimiento tanto durante como hasta 6 meses después de haber suspendido estos medicamentos. Finalmente, pacientes que en el pasado hayan padecido de TBC o cuyos síntomas junto con las pruebas anteriormente mencionadas la sugieran es mandatorio que sean previamente evaluados por neumología vs. infectología y solo se les puede iniciar dicha terapia después de un concepto favorable por uno de estos especialistas.

Hay ciertos parámetros y precauciones que se deben seguir en pacientes que reciban inmunomoduladores o terapia inmunosupresora. Existe una serie de contraindicaciones absolutas y relativas para el uso de agentes biológi$\cos (29)$ (tabla 7).

Tabla 7. Precauciones y contraindicaciones del uso de agentes biológicos.

\begin{tabular}{l}
\hline Contraindicaciones absolutas \\
\hline Alergia a proteínas de origen murino (para IFX) \\
Insuficiencia cardíaca congestiva moderada-grave (Clase III-IV NYHA) \\
Enfermedades neurológicas desmielinizantes (neuritis óptica o \\
esclerosis múltiple) \\
Contraindicación relativa: familiar en primer grado con enfermedad \\
desmielinizante) \\
Malignidad o procesos linfoproliferativos \\
Estados premalignos excepto: \\
Cáncer de piel no melanoma adecuadamente tratado \\
Malignidad diagnosticada y tratada adecuadamente hace más de \\
10 años \\
Procesos infecciosos activos \\
Úlcera crónica de miembros inferiores \\
Infección respiratoria crónica o recurrente \\
Cateterismo vesical intermitente \\
Infecciones bacterianas activas (especial atención a abscesos) \\
Infecciones virales activas no tratadas (especial atención al VHB) \\
Incluidas: infección activa por varicela, virus de Epstein-Barr (VEB), \\
herpes, gripe. \\
Infecciones por hongos y parásitos \\
TBC activa o latente no tratada \\
Vacunación reciente (< 3 semanas) con gérmenes vivos \\
\hline Contraindicaciones relativas \\
\hline Reacciones graves previas al fármaco \\
Estenosis intestinales no inflamatorias \\
Infección por VIH \\
Lupus eritematoso sistémico \\
\hline
\end{tabular}

Aunque no hace parte de la evaluación en consulta del paciente deseo esbozar a continuación de manera breve los criterios diagnósticos histológicos e imagenológicos para que el clínico tenga claro lo que debe analizar cuando evalúe los exámenes con los que debe llegar el paciente o, en su defecto, solicitarlos.

\section{CARACTERISTICAS ENDOSCOPICAS}

Siempre que se sospeche el diagnóstico de EC, se debe hacer una colonoscopia con intubación ileal (18), debido a la alta frecuencia de su compromiso. Endoscópicamente se encuentra mucosa asimétrica con dos tipos de úlceras: lineales, serpentiginosas, profundas con afectación transmural, discontinuas espaciadas por mucosa normal (18) y el segundo patrón son ulceraciones aftoides de 1 a $2 \mathrm{~mm}$ de diámetro que aparecen sobre los folículos linfoides. El compromiso es segmentario pudiendo acompañarse con estenosis (19), pero siempre recordar que esta enfermedad puede afectar cualquier segmento del tubo digestivo.

Antes del uso de la videocápsula endoscópica (VCE) debe realizarse una ileocolonoscopia, al igual que imágenes radiológicas multicortes seccionales del intestino delgado. La VCE debe ser reservada para los casos en los cuales la ileocolonoscopia más las imágenes radiológicas del intestino delgado no sean concluyentes, pero la sospecha de EC es alta (18). Una VCE normal tiene un alto valor predictivo negativo para el diagnóstico de EC del intestino delgado activa.

\section{CARACTERÍSTICAS HISTOPATOLÓGICAS}

La forma más temprana de una lesión por EC es la infiltración focal de la cripta por neutrófilos epiteliales. Se encuentra distorsión e inflamación discontinua de la arquitectura críptica, criptitis focal y granulomas epitelioides no caseificantes que pueden afectar todas las capas intestinales, nódulos linfáticos, mesenterio, peritoneo o hasta el hígado. La EC se caracteriza principalmente por úlceras "saltonas" espaciadas entre sí por mucosa normal, claramente demarcadas con compromiso transmural que afecta toda la pared intestinal volviéndola gruesa y fibrótica con estrechamiento de la luz. También afecta la grasa mesentérica engrosándola la cual da la impresión de querer atrapar y rodear el asa, fenómeno llamado como "grasa reptante". Es difícil la diferenciación histológica entre la CU y la EC, e incluso, en algunas ocasiones (hasta en $15 \%$ de las veces), nunca es posible diferenciarlas (20) denominándose con colitis no clasificada y solo cuando se extrae y analiza el espécimen quirúrgico sin poder llegarse a una conclusión definitiva se denominará colitis indeterminada.

\section{CARACTERÍSTICAS IMAGENOLÓGICAS}

La disponibilidad de modalidades de imágenes multiplanares como la resonancia magnética e imágenes por tomografía permiten no solo una evaluación completa de la pared intestinal (especialmente del intestino delgado) sino también de estructuras extraluminales. El aporte de estas imágenes es esencial para el diagnóstico inicial, el segui- 
miento y la detección de complicaciones como la presencia de estenosis, fístulas, y sospecha de abscesos $(21,22)$. Su selección por parte del clínico dependerá de la experiencia y la disponibilidad local.

La ecografía transabdominal tiene varias ventajas para la evaluación de la EII, entre estas están su disponibilidad rápida, no utilizar radiación ionizante, permitir una evaluación directa de la morfología (engrosamiento de la pared) y signos clínicos como es el dolor localizado. En manos expertas, la sensibilidad del ultrasonido en EC ha sido reportada tan alta como hasta de $80-90 \%$ para compromiso del intestino delgado o para diagnóstico de estenosis (21).

La resonancia magnética y la tomografía computarizada (TC) complementan las imágenes convencionales como el tránsito intestinal, mientras que la última da una visión más detallada de la mucosa intestinal, las imágenes multicorte permiten la evaluación completa de la pared intestinal y de las estructuras extraluminales por lo cual han ido reemplazando a estas. La TC es usada para detectar complicaciones (abscesos, estenosis) por fuera de la pared intestinal especialmente en la EC; y muestra una especificidad superior a $90 \%$ para detectar zonas de inflamación mientras que la sensibilidad varía entre $70-80 \%$ ya que alteraciones muy pequeñas de la mucosa no son detectadas (22).

La resonancia tiene un rendimiento diagnóstico similar a TC con la ventaja de no utilizar radiación ionizante en la evaluación de zonas de estenosis, y determinar el grado de compromiso de la enfermedad (22).

En resumen, estas modalidades de imágenes son promisorias para el diagnóstico inicial que involucre el intestino delgado, detectar el compromiso extraluminal como nódulos linfáticos y grasa mesentérica, identificar el grado y extensión de la inflamación del colon y la detección de complicaciones.

\section{TRATAMIENTO}

El objetivo del tratamiento es controlar síntomas al inducir remisión pero aún más importante es garantizar ese estado de remisión clínica lo cual significa la ausencia total de síntomas, libre de esteroides, biomarcadores negativos, cicatrización mucosa y sin lesiones extraluminales. Todo lo anterior con el propósito final de inducir a través de la terapia un estado de remisión profunda sostenida y así mejorar la calidad y cantidad de vida al disminuir o evitar complicaciones a corto, mediano y largo plazo (ausentismo laboral, hospitalizaciones, cirugías, cáncer colorrectal, etc.).

La terapia actual se debe estructurar de acuerdo a la presentación clínica de la enfermedad, la extensión y gravedad de esta, respuestas anteriores a tratamientos y existencia de complicaciones.
Existen unas consideraciones muy importantes para tener en cuenta desde que se inicia la terapia convencional y siempre tenerlas presentes revisándolas a medida que se avanza en el tratamiento:

1. Desde el principio identificar a los pacientes de mal pronóstico (tabla 8)

2. Iniciar tempranamente los inmunomoduladores, optimizándolos a la dosis máxima estándar $(2,5 \mathrm{mg} / \mathrm{kg}$ Aza o $1,5 \mathrm{mg} / \mathrm{kg}$ de 6-MP) sin prolongar su uso si no se logra la remisión completa en el tiempo establecido (10 a 12 semanas).

3. Reevaluar al paciente en los periodos requeridos de acuerdo a medicación que estén recibiendo:
a. Prednisona: 2 a 4 semanas
b. Azatioprina: 10 a 12 semanas
c. Salicilatos: 12 semanas.

4. Evitar el uso de esteroides (nunca subestimar la toxicidad de estos) 2 o más veces en el mismo año.

5. Cumplir con los paradigmas del control de la EII:
a. Remisión clínica
b. Libre de esteroides
c. Biomarcadores negativos
d. Cicatrización mucosa
e. Ausencia de lesiones extraluminales.

Tabla 8. Cuándo se debe considerar el uso de agentes biológicos.

\section{Intratabilidad}

Se define como la persistencia clínica, paraclínica o bioquímica de la actividad inflamatoria a pesar de adherencia al tratamiento optimizado.

Pacientes que sean esteroideo-dependientes (aquellos a los cuales no se les puede disminuir los esteroides a menos de $15 \mathrm{mg}$ de prednisona o equivalente so pena de reactivación inflamatoria 0 recaída en los primeros 3 meses después de haberlos suspendido) 0 esteroideo-resistente (aquellos que no responden ni disminuyen su actividad inflamatoria a dosis de $25 \mathrm{mg}$ o más de prednisona 0 equivalente).

Necesidad de hospitalización o cirugía.

\section{Carga inflamatoria y localización de EC}

Enfermedad perianal, gastroduodenal, compromiso intestinal extenso $(>100 \mathrm{~cm})$, enfermedad fistulizante, ulceración endoscópica profunda.

Manifestaciones extraintestinales como sacroileítis, espondilitis anquilosante, pioderma gangrenoso y uveítis.

\section{Predictores de mal pronóstico}

Edad de inicio de la enfermedad menor de 40 años, fumador, uso de esteroides 20 más veces en el mismo año, >12 meses de síntomas incapacitantes, hospitalizaciones y cirugías resectivas, pérdida de peso ( $>5 \mathrm{~kg}), \mathrm{PCR}$, eritrosedimentación y trombocitosis persistentemente altas a pesar del tratamiento óptimo. 


\section{CONCLUSIÓN}

La EC, aunque es la menos frecuente dentro de la EII en nuestro medio es la que epidemiológicamente tiene mayores tasas de crecimiento con cifras altas de morbilidad y de costos socioeconómicos; por lo tanto, estas circunstancias nos obligan moral y académicamente a unir esfuerzos para que con un objetivo mancomunado tengamos unos derroteros claros con listas de chequeo prácticas para un diagnóstico más temprano, con un mejor enfoque terapéutico lo cual redundará en menores tasas de morbimortalidad y de costos, lo cual es un aporte importante al desarrollo y bienestar de nuestra especialidad, de la sociedad y de nuestros pacientes que son en últimas, nuestra razón de ser.

\section{Agradecimiento}

Agradezco de manera especial al doctor Fernando Gomollón, presidente del Grupo Español de Trabajo para Enfermedad de Crohn y Colitis Ulcerosa (GETECCU), la gentileza en la revisión y sus valiosas sugerencias para la elaboración del presente artículo con estándares internacionales.

\section{ANEXO}

\section{LISTA DE CHEQUEO EN ENFERMEDAD DE CROHN (EC)}

\section{HISTORIA CLÍNICA}

a. Edad de inicio de la EC:

b. Historia personal:

i. Laboral

ii. Antecedentes tóxicos
1. Cigarrillo: $\mathrm{Si}$ No Cantidad/Duración

iii. Antecedentes gineco-obstétricos (Fecha última menstruación)

iv. Calidad de vida

c. Historia familiar de EII: Si Cuál

No

d. Historia de la EC:

i. Localización de la EC:
L1: Íleon
L2: Colon
L3: Íleon y colon
L4: Digestivo superior aislado p: Perineal

ii. Tratamientos previos EC

1. Mesalazina / Sulfasalazina
a. Dosis - duración

2. Esteroides
a. Dosis - duración

3. Inmunomoduladores (AZA/6-MP)

a. Dosis - duración
4. Biológicos (Adalimumab-Infliximab)

a. Cual - dosis - duración

iii. Cirugías previas EC

1. Cuál:

a. Resección: $\mathrm{Si}$ No Extensión

iv. Hospitalizaciones:
1. $\mathrm{Si}$ No

2. Motivo:

v. Manifestaciones extraintestinales

1. Dermatológicas:

a. Pioderma gangrenoso y eritema nodoso

2. Ocular

a. Uveítis, iritis, epiescleritis y escleritis

3. Articular

a. Artropatía periférica y axial, espondilitis anquilosante

4. Complicaciones secundarias a la EII

a. Cálculos renales, uropatía obstructiva, malabsorción y colelitiasis

5. Otros trastornos

a. Osteoporosis, enfermedades hepáticas, amiloidosis, complicaciones vasculares, hematológicas, pulmonares, cardiacas y neurológicas.

\section{EVALUACIÓN DE LA EXTENSIÓN/GRAVEDAD} DE LA EC

a. Síntomas cardinales:

i. Dolor abdominal, diarrea (nocturna y crónica), fiebre, pérdida de peso, sangrado rectal, fistulas, abscesos o masa abdominal.

b. Clasificación de Montreal:

\begin{tabular}{|c|c|c|}
\hline $\begin{array}{l}\text { Edad de diagnóstico } \\
\text { (A) }\end{array}$ & Localización (L) & Comportamiento (B) \\
\hline A1: Menor de 16 años & L1: Îleon & $\begin{array}{l}\text { B1: No estenosante, ni } \\
\text { penetrante (inflamatorio) }\end{array}$ \\
\hline A2: Entre 17 y 40 años & L2: Colon & B2: Estenosante \\
\hline \multirow[t]{2}{*}{ A3: Mayor de 40 años } & L3: Íleon y colon & $\begin{array}{l}\text { B3: Penetrante } \\
\text { (fistulizante) }\end{array}$ \\
\hline & $\begin{array}{l}\text { L4: Digestivo } \\
\text { superior aislado }\end{array}$ & P: Enfermedad perineal \\
\hline
\end{tabular}

Paraclínicos:

i. Laboratorios:

1. Hemograma completo + sedimentación

2. Proteína $\mathrm{C}$ reactiva (PCR)

3. Calprotectina

4. Parámetros nutricionales
a. Proteínas totales
b. Albúmina
c. Prealbúmina
d. Hierro sérico
e. Ferritina 

f. Transferrina
g. Vitamina D
h. Glicemia
i. Vitamina B12

5. Perfil hepático
a. Transaminasas (TGO-TGP)
b. Fosfatasas alcalinas
c. Bilirrubinas

6. Perfil lipídico
a. Colesterol total (HDL-LDL-VLDL)
b. Triglicéridos

7. Función renal
a. Creatinina
b. BUN

8. Citoquímico de orina

9. En casos de duda frente a tipo de EII a. pANCA y ASCA

10. Prueba de embarazo (si aplica)

ii. Colonoscopia con intubación ileal + toma biopsias representativas (en caso de no tener una confiable menor a 3 años)

iii. Imagenología abdominal (de acuerdo a la disponibilidad del recurso)

1. Ecografía transabdominal

2. Resonancia nuclear magnética (RNM)

3. Tomografía axial computarizada (TAC)

3. En caso de considerar el uso de terapia biológica:

a. Títulos de anticuerpos para parotiditis, sarampión y rubéola (MMR) varicela, hepatitis A (antiHA) y $\mathrm{B}$ (antiHBc-antiHBs-AgHBs) y C (antiHC)

Enfoque de acuerdo a resultado serológico de Hepatitis B:

\begin{tabular}{|c|c|c|c|c|}
\hline Transaminasas & AgHBs & AntiHBc & AntiHBs & Conducta \\
\hline Normal & - & - & - & Vacunar \\
\hline Normal & - & + & + & $\begin{array}{c}\text { Inmune por } \\
\text { infección natural }\end{array}$ \\
\hline Normal & - & + & - & $\begin{array}{l}\text { Infección oculta } \\
\text { Riesgo 5-10\% }\end{array}$ \\
\hline Normal & - & - & + & Vacunado \\
\hline Normal & + & + & - & Portador crónico* \\
\hline Anormal & + & + & - & Hepatitis crónica* \\
\hline
\end{tabular}

b. Serologías:
i. VIH Elisa
ii. VDRL
iii. Tuberculina (PPD)
c. Radiografía de tórax (PA y lateral)

Enfoque de acuerdo a resultado de PPD para inicio terapia biológica:

\begin{tabular}{|c|c|c|}
\hline Resultado PPD & Acción & Aplicación biológica \\
\hline $\mathrm{PPD}<5 \mathrm{MM}$ (negativo) & Ninguna & Inmediatamente \\
\hline $\begin{array}{l}\text { PPD > } 5 \text { MM (positivo) } \\
\text { RX tórax normal }\end{array}$ & $\begin{array}{l}\text { Tratamiento } \\
\text { de TBC } \\
\text { latente }\end{array}$ & $\begin{array}{l}\text { Al mes de haber } \\
\text { comenzado la profilaxis con } \\
\text { esquema aceptado }\end{array}$ \\
\hline $\begin{array}{l}\text { PPD > } 5 \text { MM (positivo) } \\
\text { TBC activa }\end{array}$ & $\begin{array}{l}\text { Tratamiento } \\
\text { de TBC } \\
\text { activa hasta } \\
\text { resolución }\end{array}$ & $\begin{array}{l}\text { Iniciar una vez infectología } \\
\text { vs. neumología confirme } \\
\text { resolución de TBC activa }\end{array}$ \\
\hline
\end{tabular}

Esquemas de tratamiento de TBC latente:

\begin{tabular}{lll}
\hline \multicolumn{1}{c}{ Medicamento } & \multicolumn{1}{c}{ Dosis } & \multicolumn{1}{c}{ Duración } \\
\hline Isoniazida & $300 \mathrm{mg} /$ día & $6-9$ meses \\
Rifampicina & $600 \mathrm{mg} /$ día & 4 meses \\
Isoniazida + Rifampicina & $300 \mathrm{mg}+600 \mathrm{mg} /$ día & 3 meses \\
\hline
\end{tabular}

4. Densitometría ósea (si recibieron de manera crónica esteroides (más de 6 semanas no continuas de prednisolona a dosis mayores de $7,5 \mathrm{mg}$ )

5. Vacunas:

a. Tétanos, difteria y tosferina (pertussis)

b. Virus del papiloma humano (VPH) en mujeres entre los 12-26 años

c. Influenza, neumococo (en pacientes seleccionados), meningococo (en pacientes seleccionados como universitarios)

d. Hepatitis A y B.

Si no se va a iniciar la terapia biológica antes de 1 mes se pueden aplicar las vacunas de virus vivos atenuados (MMR, varicela y herpes zoster).

\section{Evaluaciones:}

1. Dermatología (cáncer de piel no melanoma aquellos recibiendo azatioprina).

2. Ginecología [citología vaginal para descartar displasia cervical asociada al papiloma virus humano $(\mathrm{PVH})]$.

\section{REFERENCIAS}

1. Sands, B. Histopathology in inflammatory bowel disease. Gastroenterology 2000; 118: S68-S82.

2. Sicilia B, Vicente R, Gomollon F. Enfermedad de Crohn y colitis ulcerosa: discusión de la epidemiologia clínica. Acta Gastroenterol Latinoam 2009; 39: 135-145.

3. Cosnes J, Gower-Rousseau C, Seksik P, et al. Epidemiology and natural history of inflammatory bowel diseases. Gastroenterology 2011; 140: 1785-1794. 
4. Shanahan F, Bernstein CN. The evolving epidemiology of inflammatory bowel disease. Curr Opin Gastroenterol 2009; 25: 1-5.

5. Moum B, Ekbom A. Epidemiology of inflammatory bowel disease - methodological considerations. Digest Liver Dis 2002; 34: 364-369.

6. Loftus CG, Loftus EV Jr., Harmsen WS, et al. Update on the incidence and prevalence of Crohn's disease and ulcerative colitis in Olmsted County, Minnesota, 1940-2000. Inflamm Bowel Dis 2007; 13: 254-61.

7. Wilson B, et al. Presentado en el 7th Congress of ECCO, Feb 16-18, 2012 Barcelona, Spain. Poster 406.

8. Arguello M, Archila PE, Sierra F, et al. Enfermedad inflamatoria intestinal. Rev Col Gastroenterol 1991; 6(4): 237-272.

9. Juliao F, Ruiz MH, Florez JF, et al. Fenotipo e historia natural de la enfermedad inflamatoria intestinal en un centro de referencia en Medellín-Colombia. Rev Col Gastroenterol 2010; 25(3): 240-251.

10. Di Palma JA, Farraye FA. Crohn's disease: the first visit. Gastroenterology and Hepatology 2011; 7(3): 163-169.

11. Vatn M H. Natural history and complications of IBD. Curr Gastroenterol Rep 2009; 11(6): 481-7.

12. Lichtenstein GR, Hanauer SB, Sandborn WJ, et al. Practice parameters committee of the American college of gastroenterology . Management of crohn's disease in adults. Am J Gastroenterol 2009; 104: 465-483.

13. Silverberg MS, Satsangi J, Ahmad T, et al. Toward an integrated clinical, molecular and serological classification of inflammatory bowel disease: report of a working party of the 2005 Montreal World Congress of Gastroenterology. Can J Gastroenterol 2005; 19(Suppl. A): 5-36.

14. Sandborn WJ, Feagan BG, Hanauer SB, Lochs H, Lofberg R, Modigliani R, Present DH, Rutgeerts P, Scholmerich J, Stange EF, Sutherland LR. Review of Activity Indices and Efficacy Endpoints for Clinical Trials of Medical Therapy in Adults with Crohn's Disease. Gastroenterology 2002; 122: 512-530.

15. Vermeire S. Serologic markers in the diagnosis and management of IBD. Gastroenterol Hepatol. 2007; 3:424-426.

16. Schoepner AM, Beglinger C, Starumann A, et al. Fecal calprotectine correlates more closely with the Simple Endoscopic Score for Crohn's disease (SES-CD) than CRP, blood leukocytes and the CDAI. Am J Gastroenterol 2010; 105: 162-169.

17. Advisory Committe on Inmunization Practices. Recommended adult inmunization Schedule 2010. Ann Intern Med 2010; 152: 36-39.

18. Bourreille A, et al. Role of small -bowel endoscopy in IBD: international OMED -ECCO consensus. Endoscopy 2009; 41: $618-637$.
19. Nikolaus S, Schreiber S. Diagnostics of inflammatory Bowel Disease. Gastroenterology 2007; 133: 1670.

20. Jenkins D, Balsitis M, Gallivan S, et al. Guidelines for the initial biopsy diagnosis of suspected chronic idiopathic inflammatory bowel disease. The British Society of Gastroenterology initiative. J Clin Pathol 1997; 50: 93-105.

21. Horsthuis K, Bipat S, Bennink R, Stoker J. Inflammatory Bowel Disease with US, MR, SCintigraphy, and CT: Metaanalysis of Prospectives Studies. Radiology 2008; 24 (1): 64-79

22. Fiorino G, Bonifacio C, Peyrin-Biroulet L, Minuti F, et al. Prospective comparison of computed tomography enterography and magnetic resonance enterography for assessment of disease activity and complications in ileocolonic Crohn's disease. Inflamm Bowel Dis 2011; 17(5): 1073-80.

23. Jowet SL, Seal CJ, Barton JR, et al. The short inflammatory bowel disease questionnaire is reliable and responsive to clinically important change in ulcerative colitis. Am J Gastroenterol 2001; 96: 2921-2928.

24. Wasan SK, Baker SE, Skolnik PR, et al. A practical guide to vaccinating the inflammatory bowel disease patient. Am J Gastroenterol 2010; 105: 1231-1238.

25. Advisory Commmitte on Inmunization Practices, Recommended adult immunization schedule: United States 2010. Ann Inter Med 2010; 152: 36-39.

26. Laass MW, Roggenbuck D, Conrad K. Diagnosis and classification of Crohn's disease, Autoimmun Rev (2014), online.

27. Bossuyt X. Serologic markers in inflammatory bowel disease. Clin Chem 2006; 52: 171-81.

28. Smith LA, Gaya DR. Utility of fecal calprotectine analysis in adult inflammatory bowel disease. World J Gastroenterol 2012; 18 (46): 6782-6789.

29. Cabriadaa J, Vera I, Domènechc E, et al. Recomendaciones del Grupo Español de Trabajo en Enfermedad de Crohn y Colitis Ulcerosa (GETECCU) sobre el uso de fármacos antifactor de necrosis tumoral en la enfermedad inflamatoria intestinal (2013). Gastroenterol Hepatol 2013; 36(3): 127146.

30. Irvine EJ, Zhou Q, Thompson AK. The Short Inflammatory Bowel Disease Questionnaire: a quality of life instrument for community physicians managing inflammatory bowel disease. CCRPT Investigators. Canadian Crohn's Relapse Prevention Trial. Am J Gastroenterol 1996; 91(8): 1571-8.

31. Rahier JF, Ben-Horin S, Chowers Y, et al. European evidence-based Consensus on the prevention, diagnosis and management of opportunistic infections in inflammatory bowel disease. Journal of Crohn and Colitis 2009.

32. Harvey RF, Bradshaw JM. A simple index of Crohn disease activity. Lancet 1980; 315(8167): 514. 